\title{
A Precautionary Approach to Assessment and Management of Shrimp Stocks in the Northwest Atlantic
}

\author{
P. Koeller \\ Science Branch, Department of Fisheries and Oceans, Bedford Institute of Oceanography, \\ P. O. Box 1006, Dartmouth, Nova Scotia Canada B2Y 4A2 \\ L. Savard \\ Science Branch, Department of Fisheries and Oceans, Maurice Lamontagne Institute, \\ P.O. Box 1000, Mont-Joli, Quebec, Canada G5H 3 Z4 \\ D.G. Parsons \\ Science Branch, Department of Fisheries and Oceans, Northwest Atlantic Fisheries Center, \\ P.O. Box 5667, St. John's, Newfoundland, Canada A1C 5X1 \\ and \\ C. Fu \\ School of Fisheries and Ocean Sciences \\ 11120 Glacier Highway, Juneau, AK 99801, USA
}

\begin{abstract}
Recent stock assessments for Atlantic Canadian shrimp (Pandalus borealis) stocks, including the Scotian Shelf, the Gulf of St. Lawrence and the Labrador-Newfoundland Shelf, were conducted using the checklist or "Traffic Light" method. Results were viewed positively by many scientists, fisheries managers and industry, and the method has since been adopted by the Northwest Atlantic Fisheries Oganization (NAFO) for "data poor" stocks. It is also being considered by other stock assessment/management organizations. A major drawback of the method in its current form is that it does not link assessments to TACs or other management controls. Modeling results suggest that "Traffic Light" scores can be linked to simple harvest control rules in a way that is consistent with shrimp stock dynamics and management requirements, creating an integrated management framework that could be useful for "data rich" as well as "data poor" stocks.
\end{abstract}

Keywords: Assessment, management, Precautionary Approach, shrimp, traffic light

\section{Introduction}

Assessment and management for many shrimp (Pandalus borealis) stocks in the Northwest Atlantic are essentially descriptive and lack biological reference points. Assessments generally consist of monitoring population changes using catch rate series and/or scientific surveys. Samples from survey and commercial catches provide general information on population structure and recruitment, but population reconstructions and formal yield projections are rare. In this system, significant changes in the monitored parameters simply serve as "signals" that a change in the TAC should be considered by management, however, there is no formal link between the two processes. This approach appears to have been successful - stock collapses are rare compared to the highly parameterized stock assessment models and management regimes used for many finfish stocks. This approach has evolved because:

1. Technical problems have prevented development of quantitative assessment models for shrimp, including uncertainties in ageing, difficulties in establishing year-class strengths, highly selective fishing gears and large stock areas.

2. Stock/recruitment relationships on which to base biological reference points can rarely be demonstrated.

3. Recruitment is believed to be largely environmentally determined.

4. Shrimp stocks are believed to be relatively resilient to overfishing. 
Recent developments, including the adoption of the Precautionary Approach (PA) by many international fisheries organizations and increasing fishing pressure on many shrimp stocks, indicate that a more rigorous approach to shrimp stock assessment and management should be adopted. Following the Northwest Atlantic Fisheries Oganization (NAFO) Scientific Council meeting in November 1998, shrimp assessment specialists met to further discuss the PA and to consider the selection of references and reference points in preparation for the next shrimp assessments. It soon became evident that the identification of quantitative reference points, targets or limits, was not possible and that efforts would concentrate on the development of stock-specific checklists that would include multiple, qualitative indicators of resource status (NAFO, MS 1998, 1998).

Assuming that the descriptive assessment methodology for shrimp is adequate under current constraints, its precautionary extension would be a clarification of the process triggering concern for stock health, and formalization of the actions taken. The nature of shrimp assessment data, including the uncertainties described above, and the complexities of evaluating disparate, often conflicting data sources, imply a semi-quantitative approach similar to that of Environmental Impact Assessment (EIA). Caddy (1996) appears to have been the first to formally propose the use of EIA methods in fisheries, including an assessment-management regime in which Limit Reference Points (LRPs) determine if stock indicators are "red" or "green" (Caddy, MS 1998). A prenegotiated suite of management responses linked to an overall "Traffic Light" score becomes progressively more severe as the number of red lights increases.

Mohn et al. (1992) first proposed the use of three qualitative categories, much like traffic light colours, to describe the status of shrimp resources in a simple way so that the TAC could be adjusted (increased, decreased or maintained) accordingly. It was recognized that the tools required for calculating adjustments to the TAC in response to observed changes in the status of the resource (i.e. quantifying the change by objective, scientific methods) were not available for shrimp generally and, therefore, adjustments had to be empirically or experimentally based. A checklist format for presenting assessment results was used in the early-1990s for Gulf of St. Lawrence shrimp, allowing cross-referencing indicators to facilitate comparisons between years and areas (Savard and Hurtubise, 1991). The format was well received within scientific peer review, by fishery managers and by stakeholders in the shrimp industry. It was found to be helpful in following the numerous indicators and their tendencies (between years, between areas and between indicators) and for understanding more clearly the rationale leading to the assessment of resource status.

Regional stock assessments for shrimp in the Estuary and Gulf of St. Lawrence, the NewfoundlandLabrador-Baffin Island offshore area and on the Scotian Shelf in 1999 were conducted using a trafficlight/checklist approach and served as a first test of the method (Savard, MS 1999; Parsons et al., MS 1999; Koeller et al., MS 1999). The purpose of this paper is a) to evaluate the method as applied to some shrimp stocks in the Northwest Atlantic and b) to use a simulation model to determine if the checklist results can be linked to harvest rules which are consistent with shrimp population dynamics and the PA.

\section{Methods}

\section{Traffic-light/checklist approach}

During the assessments of shrimp in the Gulf of St. Lawrence, on the Scotian Shelf and in the Canadian Northwest Atlantic in 1999, the resource status was determined by examining a number of indicators from the commercial fishery and research trawl surveys (Savard, MS 1999; Parsons et al., MS 1999; Koeller et al., 1999). The indicators were examined in a two-step approach: 1) observations and results of numerical analyses and, 2) biological interpretations and implications for the status of the resource. The indicators referred to underlying factors that can affect fishing success, stock abundance and/ or resource productivity. The factors were assessed from the standpoint of impact on resource status, on future abundance and stock productivity using three categories of evaluation: 1) positive outlook - green, 2) uncertainty about the magnitude of the impact yellow and 3) concerns about the current and/or future condition of the stock - red. Overall resource status was then assessed by viewing all indicators in combination. The results were presented as performance reports for each management unit.

\section{Simulation Study}

A spreadsheet population model was developed to test the validity of the "Traffic Light" approach as suggested in Caddy (MS 1998). Although Caddy suggested the use of fuzzy logic systems analysis, we felt that a relatively simple age-based model with a 
feedback mechanism i.e. a management response (setting a TAC) linked to the parameters (indicators) measured with error, would be adequate to test the hypothesis that more poorly measured or understood indicators were better than fewer. This hypothesis examines the intuitive appeal or implied advantage of the "Traffic Light" approach i.e. that any one indicator is always associated with large variances and/or uncertainty as to what a change means relative to stock status, resulting in a high risk of failure of traditional assessment-management models (e.g. projections from VPA, production models) but that additional indicators, especially when obtained from independent observations, and when considered in total, will tend to reflect the true state of the stock. In addition we wanted to determine how the method would perform relative to a traditional approach; in this case the setting of a TAC representing a fixed percentage of a measured spawning stock biomass. This is a management method currently used for some shrimp stocks, for example, on the Canadian west coast and has been used in the past on the Canadian east coast.

The model assumes that the population at the start of the simulation is pristine, with recruits to the population at age 1 and year 1 of 1000 million. Abundance $(N)$ at any age and year 1 can be derived from

$$
N_{a, 1}=N_{a-1,1} e^{-M_{1}}
$$

where $M$ is natural mortality. Catch $(C)$ at age from age 2 is obtained from

$$
C_{a, t}=N_{a-1, t-1} \mu_{t} S_{a} e^{-M_{t} / 2}
$$

Abundance for animals from age 2, which have experienced natural mortality and fishing is obtained from

$$
N_{a, t}=\left[N_{a-1, t-1} e^{-M_{t} / 2}-C_{a, t}\right] e^{-M_{t} / 2}
$$

Since few stock recruitment relationships have been demonstrated or described for $P$. borealis, recruitment was linked to spawning stock through a hypothetical relationship which was identical for all simulation runs and included a process error (CVs of $60 \%$ ). Surveys for spawning stock biomass and recruits were simulated by applying lognormal measurement errors to the actual spawner and recruit abundance. Environmental/ecological indicators, for example, the abundance of groundfish predators, were represented in the model only by natural mortality, which was assumed to be measurable, and was generated randomly as an annual value between a preset range of 0.3 and 0.9 .

Other basic model parameters were set using average values from the Scotian Shelf shrimp stock, including 6 year-classes, in which the first 4 are juveniles and males, and the last two are spawning females. Consequently, there was no variation in the age at sex change or first spawning. Weights-at-age were constant for each age using average values obtained from Scotian Shelf survey samples. Selectivity and recruitment to the fishery was also constant at each age with average values based on sampling of commercial catches on the Scotian Shelf.

Six stock indicators were used in the simulations, each of which was scored according to criteria which were more or less arbitrary, albeit realistic in terms of model dynamics, i.e. criteria were adjusted if necessary from initial run results to give a reasonably large range of scores for all indicators for the 50-year simulations. The criteria used are given in Table 1.

Average age and sex ratio were chosen to represent indicators whose meaning relative to stock health is ambiguous. For example, a change in sex ratio could signal both positive, negative (increasing or decreasing recruitment, increasing or decreasing

TABLE 1. Criteria used to score stock status indicators in the simulation model.

\begin{tabular}{lcc}
\hline \hline Indicator & Criteria & Respective Scores \\
\hline Recruitment & $>0.5,0.2-0.5,<0.2$ of virgin & $1,0,-1$ \\
Spawning Stock Biomass & $>0.5,0.2-0.5,<0.2$ of virgin & $1,0,-1$ \\
Environment & $\mathrm{M}<0.5,0.5-0.6,>0.6$ & $1,0,-1$ \\
Number of age-classes & $>4,3-4,<3$ & $1,0,-1$ \\
Average age & $<2.5,>3$ & $-1,0,-1$ \\
Sex ratio & $<2,>4$ & $-1,0,-1$ \\
\hline
\end{tabular}


survival of older animals) or unknown (e.g. rate of sex reversal) changes in the population structure. Despite their ambiguity, such indicators may still be useful if incorporated into the analysis in a "precautionary way", i.e. if the meaning of a change relative to the health of the stock is ambiguous, the PA would be to assume any change outside a given range signals instability and is bad. Consequently these two indicators were scored as -1 if they fell outside a range, and 0 of they fell within it.

The annual "assessment" consisted of the arithmetic sum of the individual parameter scores. The feedback mechanism consisted of a simple harvest rule connecting the sum score from year $t$ to the TAC for year $t+N$. The TAC was calculated as the percentage of the Spawning Stock Biomass (SSB) determined from the harvest rule and the survey mean estimate of SSB. Harvest rules were developed for sum scores derived from 3 indicators (spawning stock, recruitment and natural mortality), and for all six indicators as in Table 2, where the numbers indicate increases or decreases in the exploitation rate (i.e. percent of the survey SSB) from the previous year. Rule 2 was set so that scores of 3 or greater and -3 or less invoked the same response as the maximum (3) and minimum (-3) scores for 3 indicators (Rule 1), thus making them comparable in terms of dynamic range. Rule 3 uses a more symmetrical range of possible scores. Rule 4 was more "aggressive" than Rule 3 in that it increased exploitation above a score of 0 more rapidly than it decreased it below 0 . Rule 5 was set to determine the effect of higher weighting for parameters deemed to have higher quality data. In this case the scores of 1 , 0 , and -1 used for all parameters in Rules $1-4$ were changed to 3, 0 and -3 for recruitment and SSB, the two parameters determined by surveys. Yields and risks are presented as the mean of each 50-year simulation run. Risk was determined as the percentage of years in which the spawning stock declined below an arbitrary $10 \%$ of the virgin biomass in each run. Simulations were run with initial (for runs using rules) and constant exploitation rates ranging from 0.1 to 0.6 .

\section{Results}

\section{Traffic-light/checklist Approach}

Gulf of St. Lawrence. The assessment in winter 1999 used three categories of evaluation but the analogy of the traffic lights was not directly applied. It was thought that the concepts of uncertainty or concern were more appropriate to describe the meaning of the indicators. An example of the method as used for the Sept Îles fishery is given in Table 3. Indicators used in the assessment were grouped under three headings: fishing success, stock abundance and resource productivity. Most indicators provided a positive outlook and reflected the current high

TABLE 2. Harvest rules applied in the simulation model. Numbers under each rule represent the percent change in exploitation rate associated with each score. Scores represent the sum of the annual individual parameter scores of 0,1 or -1 . Rule 1 uses only natural mortality, recruitment and spawning stock biomass indicators to set exploitation rates. Rule 2 uses all 6 indicators but is maximized at a score of 3 to make it comparable to Rule 1. Rule 3 uses the full dynamic range of 6 indicators, while Rule 4 is more aggressive with good scores. Rule 5 is comparable to Rule 3 but weights the two survey indicators 3 times higher than the other indicators.

\begin{tabular}{crrrrr}
\hline \hline & 3 Indicators & & \multicolumn{3}{c}{ 6 Indicators } \\
\cline { 2 - 5 } \cline { 4 - 6 } Scores & Rule 1 & Rule 2 & Rule 3 & Rule 4 & Rule 5 \\
\hline 4 & & 0.33 & 0.165 & 0.33 & 0.165 \\
3 & 0.33 & 0.33 & 0.165 & 0.33 & 0.165 \\
2 & 0.165 & 0.165 & 0.11 & 0.165 & 0.11 \\
1 & 0.11 & 0.11 & 0.11 & 0.165 & 0.11 \\
0 & unchanged & unchanged & unchanged & unchanged & unchanged \\
-1 & -0.11 & -0.11 & -0.11 & -0.11 & -0.11 \\
-2 & -0.165 & -0.165 & -0.11 & -0.11 & -0.11 \\
-3 & -0.33 & -0.33 & -0.165 & -0.165 & -0.165 \\
-4 & & -0.33 & -0.165 & -0.165 & -0.165 \\
-5 & & -0.33 & -0.33 & -0.33 & -0.33 \\
-6 & & -0.33 & -0.33 & -0.33 & -0.33 \\
\hline
\end{tabular}


biomass/abundance, large spawning stock and no increase in exploitation during the 1990s. The impact of observed spatial and temporal changes in fishing pattern was uncertain, as was the increase in Greenland halibut abundance with respect to predation mortality. The only "cause for concern" was the low numbers of small males encountered in the 1998 trawl survey that suggested low recruitment to the fishery. The overall assessment, based on combination of all indicators concluded that the stock was in good condition in 1998 but, because of lower recruitment, could begin to decline in 1999. Therefore, stock status was somewhat uncertain in that it was not possible to quantify the future effect of reduced recruitment on either fishery performance or stock status.

The indicators are not totally independent as some could represent correlated factors or different states of the same variable. For example, the abundance of males is used as an indication of the strength of the recruitment to the fishery. Therefore, it is believed to be linked to the abundance of females, the survey biomass and the fishery catch rates some years later. From this point, it became interesting to do a retrospective analysis to see how the performance report and the series of indicators could show the evolution of a stock over many years. The exercise was done for the Gulf of St. Lawrence Sept-Îles management unit for which two series of nine years of survey and seventeen years of fishery data were available. Annual performance reports were built for the research survey period (1990 to 1998) with data available up to the year of analysis (Table 4). The retrospective analysis shows how the "waves" of poor or strong year-classes spread from one indicator to the other over time and how this affects the overall status of the stock.

Baffin Island, Labrador and northeastern Newfoundland. Assessment of northern shrimp within four areas in the Canadian Northwest Atlantic in winter 1999 followed the approach used for the Gulf of St. Lawrence (i.e. observation, interpretation and evaluation of indicators) but used the traffic light analogy more directly. An example of the method as applied to Hawke Channel and Div. $3 \mathrm{~K}$ is given in Table 5. Indicators relevant to stock status were grouped under fishery data, research data and ancillary data. The first two groupings included the traditional data sources used in stock assessments whereas the last attempted to incorporate other factors that are believed to be important in determining the status of shrimp stocks but seldom find their way into the process. Most indicators were evaluated positively (green lights) and there were no immediate concerns regarding either current status or future prospects (red lights). Two indicators addressing recruitment were evaluated as uncertain (yellow lights): survey results indicated that the 1995 and 1996 year classes were weaker than those of 1993 and 1994 and warmer than average water temperatures from 1996 to 1998 could result in reduced recruitment to the fishery. The overall assessment, based on the combination of all indicators, concluded that the current status was favourable with high biomass/abundance of male and female components. Future prospects were uncertain, however, given that the available data suggested a decline in recruitment.

Assessments were carried out for the other three areas using the same method and the results for all four areas are summarized in Table 6. The summary showed clearly how uncertainty in resource status increased from south to north. No evaluation was given where data were absent. In the example provided in Table 5, data from both the commercial fishery and research trawl surveys were reliable. The uncertainty about recruitment was two-fold: uncertainty that the recruitment index was reliable with such a short time series and uncertainty about how any realized reduced recruitment will impact overall stock status. In the Hopedale and Cartwright area, fishery data were considered reliable but research data were uncertain regarding trend because the survey design did not resolve the patchy distribution on shrimp in this area. A similar situation was evident in Div. $2 \mathrm{G}$ with the addition that industry, itself, was uncertain about the stock distribution in this area. Div. 0B lacked research trawl surveys and the fishery data were difficult to interpret because of the mixed-species fishery ( $P$. borealis/montagui) in the main fishing area and the uncertainty about population structure and boundaries.

\section{Simulation Study}

Model runs with constant exploitations rates from $0.1-0.6$ resulted in an asymptotic curve similar to most yield-per-recruit analyses for Pandalid shrimp including a maximum yield at relatively high exploitation rates (Fig. 1A). This result validates the model's basic structure and provides a means for comparing "Traffic Light" results with a traditional yield analysis. Of particular interest in the constant exploitation runs is the sharply increasing level of risk (Fig. 1B) and the decreasing yield-per-unit risk (Fig. 1C) as exploitation rates increase. This is in contrast to runs with harvest rules based on traffic light results, where risk increases much more 
TABLE 3. Performance report for Sept Îles for 1999. Evaluations are + (green) positive, 0 (yellow) uncertain, $r$ - (red) negative.

\begin{tabular}{|c|c|c|c|}
\hline INDICATOR & OBSERVATION & INTERPRETATION & EVALUATION \\
\hline \multicolumn{4}{|c|}{ FISHING SUCCESS } \\
\hline Landings & $\begin{array}{l}40 \% \text { increase in TACs and landings since } \\
1995 ; \text { TAC taken easily since } 1995\end{array}$ & Large biomass & + \\
\hline Catch (number) & $\begin{array}{l}19 \% \text { increase since } 1995 \text {; decrease in males } \\
(12 \%) \text {, increase in females }(62 \%)\end{array}$ & $\begin{array}{l}\text { High abundance; mean weight of catches } \\
\text { has increased }\end{array}$ & + \\
\hline Effort & $\begin{array}{l}40 \% \text { reduction between } 1994 \text { and } 1995 ; \\
\text { effort low and stable since } 1995\end{array}$ & High density & + \\
\hline Seasonal pattern & $\begin{array}{l}\text { High monthly CPUEs in 1998; CPUEs } \\
\text { decline over season }\end{array}$ & $\begin{array}{l}\text { High density; return to seasonal pattern of } \\
\text { early } 1980 \text { s }\end{array}$ & $\mathbf{0}$ \\
\hline Spatial pattern & $\begin{array}{l}\text { Effort reduced in southern part of Laurentian } \\
\text { Channel; effort increased in western part of } \\
\text { area }\end{array}$ & $\begin{array}{l}\text { Change in distribution; geographic range } \\
\text { may be shrinking }\end{array}$ & $\mathbf{0}$ \\
\hline Stock distribution & $\begin{array}{l}\text { Drop in densities in southern part of } \\
\text { Laurentian Channel; increase in densities in } \\
\text { western part of area }\end{array}$ & $\begin{array}{l}\text { Change in distribution; geographic range } \\
\text { may be shrinking }\end{array}$ & $\mathbf{0}$ \\
\hline Industry perception & $\begin{array}{l}\text { Good concentrations of shrimp in areas } \\
\text { different from other years; few or no small } \\
\text { shrimp }\end{array}$ & $\begin{array}{l}\text { Densities still high, but change in } \\
\text { distribution and low recruitment }\end{array}$ & $\mathbf{0}$ \\
\hline
\end{tabular}

\begin{tabular}{|l|l|l|c|}
\hline STOCK ABUNDANCE & \multicolumn{2}{|l|}{} & + \\
\hline Biomass index & $\begin{array}{l}\text { Increasing since 1992-93; 1998 stable in } \\
\text { relation to 1997; 1997 and 1998 values } \\
\text { highest in series }\end{array}$ & Large biomass & + \\
\hline CPUE & $\begin{array}{l}\text { Increasing since 1992-93; 1998 value } \\
\text { highest in series }\end{array}$ & High density & + \\
\hline Abundance index & $\begin{array}{l}\text { Increasing since 1992-93; 1998 stable in } \\
\text { relation to 1997; 1997-98 values similar to } \\
\text { that of 1990 }\end{array}$ & High abundance & + \\
\hline NPUE & $\begin{array}{l}\text { Increasing since 1992-93; 1998 value } \\
\text { highest in series }\end{array}$ & High density & + \\
\hline
\end{tabular}

\section{RESOURCE PRODUCTIVITY}

\begin{tabular}{|c|c|c|c|}
\hline Population structure & $\begin{array}{l}\text { Age structure stable from year to year; } \\
\text { growth gradient from east to west }\end{array}$ & $\begin{array}{l}\text { No loss of female component; productivity } \\
\text { lower in eastern part of Gulf }\end{array}$ & + \\
\hline Size of males & Size of last mode of males smaller in 1998 & $\begin{array}{l}\text { Size at sex change will drop in } 1999 ; \\
\text { females will be smaller }\end{array}$ & $\mathbf{0}$ \\
\hline Size of females & Increasing since 1994; very big in 1998 & Fewer individuals for same catch & + \\
\hline Female abundance & $\begin{array}{l}\text { Increasing since } 1992-93 ; 1998 \text { value } \\
\text { highest in series }\end{array}$ & Large spawning stock & + \\
\hline Male abundance & $\begin{array}{l}\text { Abundance of all male components } \\
\text { relatively stable in 1992-96, but fell in } 1998 \\
\text { to average level }\end{array}$ & Average recruitment to spawning stock & 0 \\
\hline Recruitment & $\begin{array}{l}\text { Drop in male abundance to average level; } \\
\text { very few small males in } 1998 \text { survey }\end{array}$ & Low recruitment to fishery & - \\
\hline Predation & $\begin{array}{l}\text { Cod and redfish abundance low, but increase } \\
\text { in turbot }\end{array}$ & Predation pressure will rise & 0 \\
\hline Exploitation rate & $\begin{array}{l}\text { No increase with recent rise in catches; } 1998 \\
\text { rates were same as those of early } 1990 \mathrm{~s}\end{array}$ & $\begin{array}{l}\text { Fishing mortality has not increased since } \\
\text { early } 1990 \mathrm{~s}\end{array}$ & + \\
\hline \multicolumn{4}{|l|}{ ASSESSMENT } \\
\hline All indicators combined & \multicolumn{2}{|c|}{$\begin{array}{l}\text { Stock in very good condition in 1998, but could begin to decline in } 1999 \text { because of } \\
\text { lower recruitment }\end{array}$} & $\mathbf{0}$ \\
\hline
\end{tabular}

gradually and yield/risk decreases very little with increasing initial exploitation rates. This is to be expected in a method which decreases exploitation when there are indications of problems, versus one which takes a constant percentage of the remaining spawning stock. A comparison of results from the 5 different rules indicate that Rule 1 (3 indicators), while obtaining relatively high yields, also resulted in high risks and low yield/risk. By comparison, Rule 2 (6 indicators) had a relatively low risk and 
TABLE 4. Retrospective analysis (summary of performance reports) for Sept Îles area in the Gulf of St. Lawrence for 1990-98.

\begin{tabular}{|c|c|c|c|c|c|c|c|}
\hline$\underset{\lambda}{\grave{\lambda}}$ & 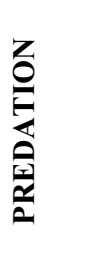 & 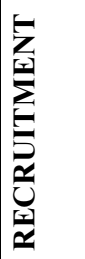 & 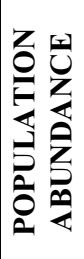 & 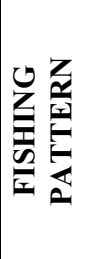 & 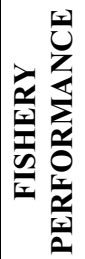 & 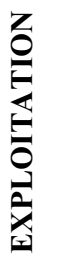 & 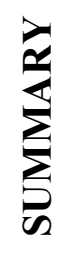 \\
\hline & & & & & & & \\
\hline 1990 & - & -- & + & + & + & + & 0 \\
\hline 1991 & -- & -- & 0 & + & 0 & + & 0 \\
\hline 1992 & 0 & -- & -- & 0 & -- & -- & -- \\
\hline 1993 & 0 & 0 & -- & 0 & -- & -- & -- \\
\hline 1994 & + & ( & 0 & 0 & 0 & 0 & 0 \\
\hline 1995 & + & + & + & + & + & 0 & + \\
\hline 1996 & + & + & + & + & + & 0 & + \\
\hline 1997 & + & + & + & + & + & + & + \\
\hline 1998 & 0 & & + & 0 & + & + & 0 \\
\hline
\end{tabular}

high yield/risk. Rule 3, which used a more symmetrical distribution of scores and responses differed little from rule 2 . Rule 4 was more aggressive in that higher positive scores allowed larger increases in exploitation rate. This resulted in relatively, high risks, low yields and low yield/risk. Finally, Rule 5, which emphasised the importance of results from the recruitment and SSB surveys, did not appear to improve significantly on the comparable unweighted Rule 3. Rule 5 did result in slightly lower risks than Rule 3, but at considerably lower yields.

\section{Discussion}

The performance report is a powerful visual tool that shows how the overall conclusion on the status of a stock is reached. It also shows the interdependance of indicators over time, for example, the abundance of males as an indicator of recruitment to the fishery is linked to the abundance of females, the survey biomass and commercial catch rates some years later. In Canada, the method has been accepted within three independent management regimes, both for the assessment process and the presentation of results to clients and stakeholders. Its appeal lies in its simplicity and comprehensiveness. All observations from the indicators considered in the process are described and interpreted in transparent terms and their strengths and weaknesses are evident. The format provides a mechanism for consensus building among scientists, fisheries managers and industry. It incorporates input from fishermen, and environmental influences such as temperature and predation, despite their qualitative nature and usual exclusion from traditional approaches.

Although the performance reports were much appreciated by fisheries managers and industry, it is recognized that the exercise has not been completed. In the current application, the overall status of the resource is a combination of all indicators without considering their precision or their implications for stock performance. The method still lacks a weighting system that could be applied to each indicator to more adequately represent their uncertainty or the importance of their impact on shrimp conservation strategies. The final developmental step would link the status of the resource to clearly defined management decisions and options. When all steps have been taken, a framework for assessment and management of shrimp should exist in the precautionary context.

A weakness of the method is the interpretation of the 0 , "uncertain" or "yellow light" category. In the performance reports given in this paper, they do not 
TABLE 5. Performance report for Hawke Channel + Div. 3K for 1999.

\begin{tabular}{|c|c|c|c|}
\hline INDICATOR & OBSERVATION & INTERPRETATION & EVALUATION \\
\hline \multicolumn{4}{|l|}{ FISHERY DATA } \\
\hline $\mathrm{CPUE}-\mathrm{kg} / \mathrm{hr}$ & $\begin{array}{l}\text { Increased for offshore fleet up to } 1996 \text { and has } \\
\text { remained at a high level ( }>2000 \mathrm{~kg} / \mathrm{hr} \text { ). Inshore } \\
\text { sector, including inexperienced fishers, had high } \\
\text { catch rates when the fishery began in } 1997 \text {. }\end{array}$ & $\begin{array}{l}\text { Reflects an increase in the resource up to } \\
1996 \text {, remaining at a high level since. }\end{array}$ & + \\
\hline Spatial pattern & $\begin{array}{l}\text { Eastward expansion in effort by offshore vessels in } \\
\text { early } 1990 \text { 's. }\end{array}$ & $\begin{array}{l}\text { Reflects the discovery of high concentrations } \\
\text { of shrimp along the shelf slope during the } \\
\text { exploratory fishery in } 1992 \text { and } 1993 \text {. These } \\
\text { areas previously were thought to be } \\
\text { unproductive. }\end{array}$ & + \\
\hline Temporal pattern & $\begin{array}{l}\text { A winter-spring fishery for the offshore fleet and a } \\
\text { summer-fall fishery for the inshore fleet. }\end{array}$ & $\begin{array}{l}\text { Commercially viable concentrations of } \\
\text { shrimp available throughout the year. }\end{array}$ & + \\
\hline Male abundance & $\begin{array}{l}\text { The abundant } 1991 \text { year-class began to recruit in } \\
1994 \text { and produced higher catch rates in } 1995 \text { and } \\
1996 \text {. The } 1993 \text { year-class dominated in } 1997 \text { and } \\
1998 \text { but appears weaker than the } 1991 \text {. }\end{array}$ & $\begin{array}{l}\text { Good recruitment of year-classes produced } \\
\text { in the early } 1990 \text { 's resulted in high catch } \\
\text { rates of males since } 1995 \text {. }\end{array}$ & + \\
\hline Female abundance & $\begin{array}{l}\text { Catch rates of the female component increased } \\
\text { from } 1993 \text { to } 1996 \text { and stabilized in } 1997 \text { and } 1998 .\end{array}$ & $\begin{array}{l}\text { Continued good recruitment since the mid } \\
1980 \text { 's is responsible for the increase in } \\
\text { spawning stock throughout the 1990's. } \\
\text { Spawning component remains healthy. }\end{array}$ & + \\
\hline Sex inversion & $\begin{array}{l}\text { The median size at sex change varied between } 21 \\
\text { and } 22 \mathrm{~mm} \text { carapace length throughout the 1990's. }\end{array}$ & $\begin{array}{l}\text { Stability in maturity schedules suggests that } \\
\text { favourable sex ratios are being maintained } \\
\text { within the population. }\end{array}$ & + \\
\hline \multicolumn{4}{|l|}{$R E S E A R C H D A T A$} \\
\hline $\begin{array}{l}\text { Biomass/abundance } \\
\text { index }\end{array}$ & $\begin{array}{l}\text { The lower } 95 \% \text { confidence intervals for the } \\
\text { biomass/abundance indices averaged about } 400,000 \\
\text { tons/ } 90 \text { billion animals during the } 1996 \\
\text { to } 1998 \text { period. }\end{array}$ & High biomass/abundance. & + \\
\hline Spatial pattern & $\begin{array}{l}\text { Widely distributed throughout the management } \\
\text { area. }\end{array}$ & $\begin{array}{l}\text { Wider distribution in the } 1990 \text { 's compared to } \\
\text { the } 1980 \text { 's, reflecting higher stock size. }\end{array}$ & + \\
\hline $\begin{array}{l}\text { Recruitment } \\
\text { (male age structure) }\end{array}$ & $\begin{array}{l}\text { Survey abundance in } 1996 \text { and } 97 \text { was dominated } \\
\text { by males of the } 1993 \text { and } 1994 \text { year-classes. The } \\
1994 \text { year-class dominated in } 1998 \text {. The } 1995 \text { and } \\
1996 \text { year-classes appear weaker. }\end{array}$ & $\begin{array}{l}\text { Recruitment of males will likely decline, } \\
\text { beginning in } 1999 \text { and continuing into the } \\
\text { next millennium. }\end{array}$ & $\mathbf{0}$ \\
\hline $\begin{array}{l}\text { Spawning stock } \\
\text { (females) }\end{array}$ & $\begin{array}{l}\text { Relatively stable. Increase in } 1998 \text { survey due to } \\
\text { small females, possibly part of the } 1993 \text { year-class. }\end{array}$ & $\begin{array}{l}\text { Female abundance should be maintained in } \\
\text { the short term ( } 1999 \text { and } 2000) \text { by the } \\
\text { continued recruitment of the } 1993 \text { and } 1994 \\
\text { year-classes. }\end{array}$ & + \\
\hline \multicolumn{4}{|l|}{$A N C I L L A R Y D A T A$} \\
\hline Predation & $\begin{array}{l}\text { Abundance of known predators such as cod, } \\
\text { redfish, skate and American plaice remains low in } \\
\text { the offshore areas. }\end{array}$ & $\begin{array}{l}\text { Predation mortality remains low relative to } \\
\text { periods of high predator abundance. }\end{array}$ & + \\
\hline Environment & Warmer than average water from 1996 to 1998. & $\begin{array}{l}\text { Could result in lower catch rates (reduced } \\
\text { recruitment to the fishery) beginning in } 1999 \\
\text { and continuing into the next millennium. }\end{array}$ & $\mathbf{0}$ \\
\hline Industry perspectives & $\begin{array}{l}\text { Catch rates were high in recent years with similar } \\
\text { offshore catch rates in early } 1999 .\end{array}$ & $\begin{array}{l}\text { The resource is perceived to be healthy by } \\
\text { both inshore and offshore sectors. }\end{array}$ & + \\
\hline \multicolumn{4}{|l|}{ ASSESSMENT } \\
\hline Exploitation rate & $\begin{array}{l}\text { Ratio of nominal catch to survey biomass index } \\
\text { (lower confidence intervals) has been less than } 12 \% \\
\text { for the past } 3 \text { years. }\end{array}$ & $\begin{array}{l}\text { Catchability of the survey gear is believed to } \\
\text { be }<1 \text {. Therefore, exploitation rate likely has } \\
\text { been }<12 \% \text {. }\end{array}$ & + \\
\hline Stock Status & & $\begin{array}{l}\text { Current status favourable with high } \\
\text { biomass/abundance of male and females. }\end{array}$ & + \\
\hline Future Prospects & & $\begin{array}{l}\text { Available information suggests a decline in } \\
\text { recruitment for } 2000+\text {, so it is uncertain if } \\
\text { the current TAC can be sustained }\end{array}$ & $\mathbf{0}$ \\
\hline
\end{tabular}

represent "average" or "intermediate" conditions. Uncertainty is defined as both uncertainty in the analysis of data (e.g. variance) and uncertainty in the interpretation of the observations (i.e. stock performance). The "yellow" category could also indicate a lack of information pertaining to any indicator or performance report summary. Under the PA, greater precaution should be applied in cases with 
TABLE 6. Summary of performance reports for all shrimp fishing areas off Labrador-Newfoundland in 1999.

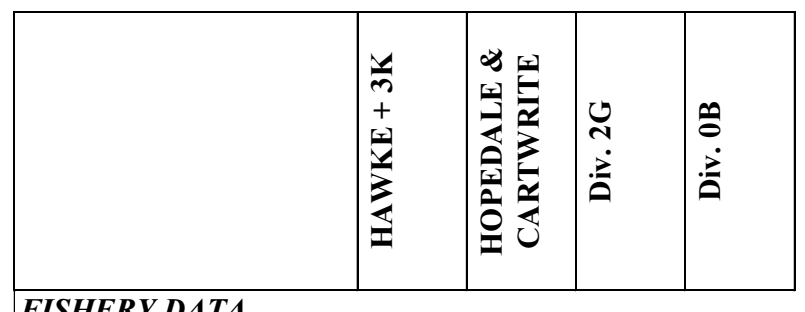

FISHERY DATA

\begin{tabular}{|l|c|c|c|c|}
\hline CPUE - KG/HR & + & + & + & $\mathbf{0}$ \\
\hline Spatial pattern & + & + & + & $\mathbf{0}$ \\
\hline Temporal pattern & + & + & & \\
\hline Male abundance & + & + & + & $\mathbf{0}$ \\
\hline Female abundance & + & + & + & $\mathbf{0}$ \\
\hline Sex inversion & + & $\mathbf{0}$ & $\mathbf{0}$ & $\mathbf{0}$ \\
\hline
\end{tabular}

RESEARCH DATA

\begin{tabular}{|l|c|c|c|c|}
\hline Biomass/abundance index & + & $\mathbf{0}$ & $\mathbf{0}$ & \\
\hline Spatial pattern & + & $\mathbf{0}$ & $\mathbf{0}$ & \\
\hline $\begin{array}{l}\text { Recruitment (male age } \\
\text { structure) }\end{array}$ & $\mathbf{0}$ & $\mathbf{0}$ & $\mathbf{0}$ & \\
\hline Spawning stock (females & + & $\mathbf{0}$ & $\mathbf{0}$ & \\
\hline
\end{tabular}

ANCILLARY DATA

\begin{tabular}{|l|c|c|c|c|}
\hline Predation & + & + & & \\
\hline Environment & $\mathbf{0}$ & $\mathbf{0}$ & & \\
\hline Industry perspective & + & + & $\mathbf{0}$ & $\mathbf{0}$ \\
\hline ASSESSMENT & & & & \\
\hline Exploitation rate & + & $\mathbf{0}$ & $\mathbf{0}$ & $\mathbf{0}$ \\
\hline Stock Status 1999 & + & $\mathbf{0}$ & $\mathbf{0}$ & $\mathbf{0}$ \\
\hline Future Prospects 2000+ & $\mathbf{0}$ & $\mathbf{0}$ & $\mathbf{0}$ & $\mathbf{0}$ \\
\hline
\end{tabular}

greater uncertainty. The appearance of yellow lights in performance reports should serve as a warning to research managers that more information is required in that area. Note that the simulations were conducted under the premise that the stock in question had a monitoring program, which provided sufficient information to dispel uncertainty. Consequently, the yellow category was not used in the same sense as in the performance reports and the 0 score in the simulations represent an intermediate state between 1 and -1 .

Simulation results provide some insight into the qualities of a management framework which links the Traffic Light method to harvest rules. For example, they appear to support the hypothesis that more indicators are better than fewer in terms of yields and risks, even when the indicators are poorly measured, or when the meaning of a change in an indicator is incompletely understood relative to stock status. It suggests that the main drawback in the "Traffic Light" method as it is currently used, i.e. no formal links between results and management decisions, could be eliminated with further development. However, note that simulation results should not be considered definitive but rather illustrative of needed research in this area, pending further investigation with more sophisticated modelling techniques. For example, with the modelling methods used it was not possible to conclude that the improved efficiency of the 6 versus 


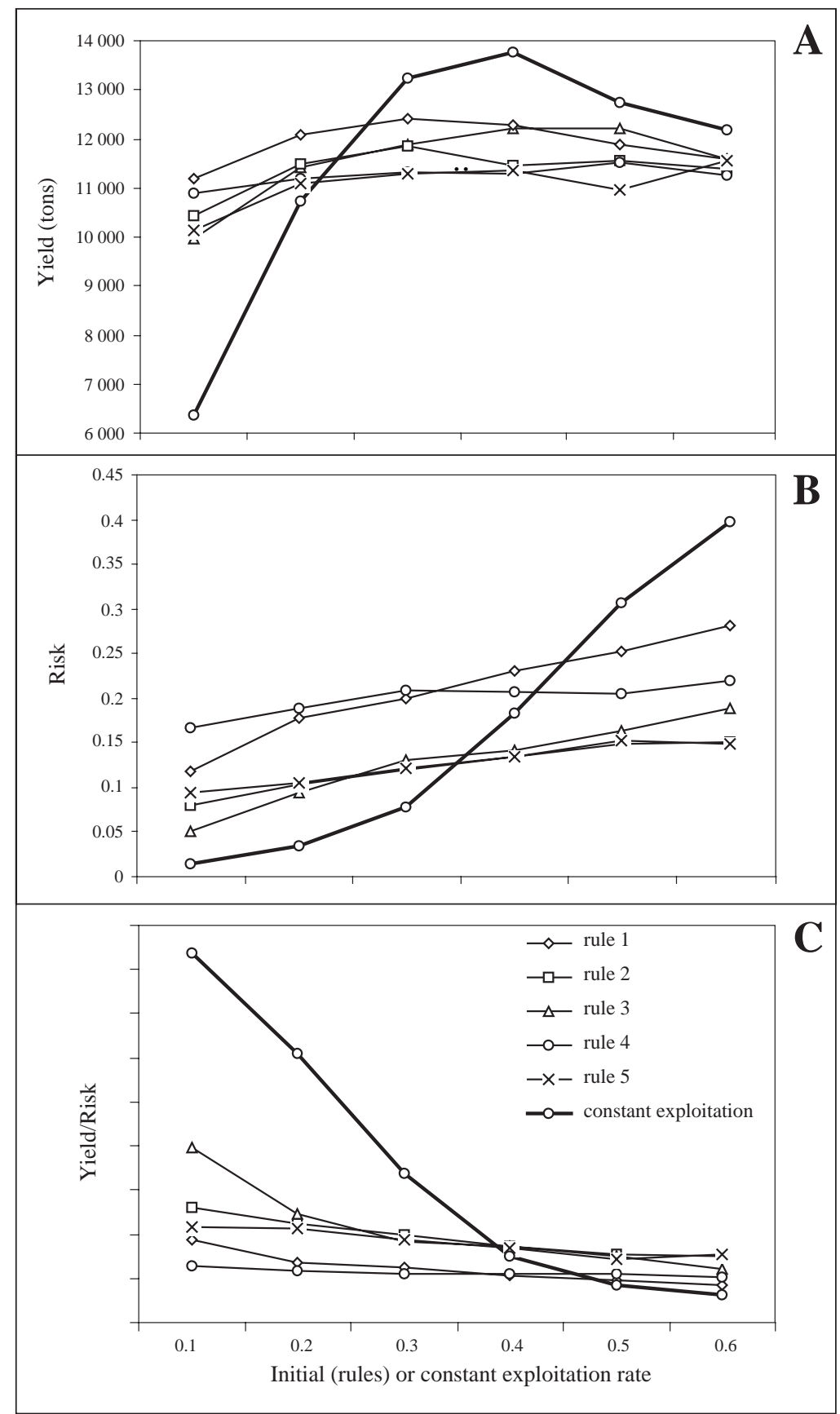

Fig. 1. Results from model runs comparing constant exploitation at exploitation rates between 0.1 and 0.6 of the spawning stock biomass and rules defined in Table 2 with initial exploitation rates between 0.1 and 0.6

3 parameter runs is due exclusively to the additional information provided by the use of additional parameters, or simply due to differences in the dynamic ranges and associated symmetry of probablilities inherent in the two rules themselves. Similarly, while results of runs with weighted parameters suggest that weighting may not be helpful, the result is counter-intuitive to some and valid only within the context of the model used. Results suggest that weighting more important parameters, for example, survey results, may simply accentuate the uncertainty (variability) inherent in these parameters, 


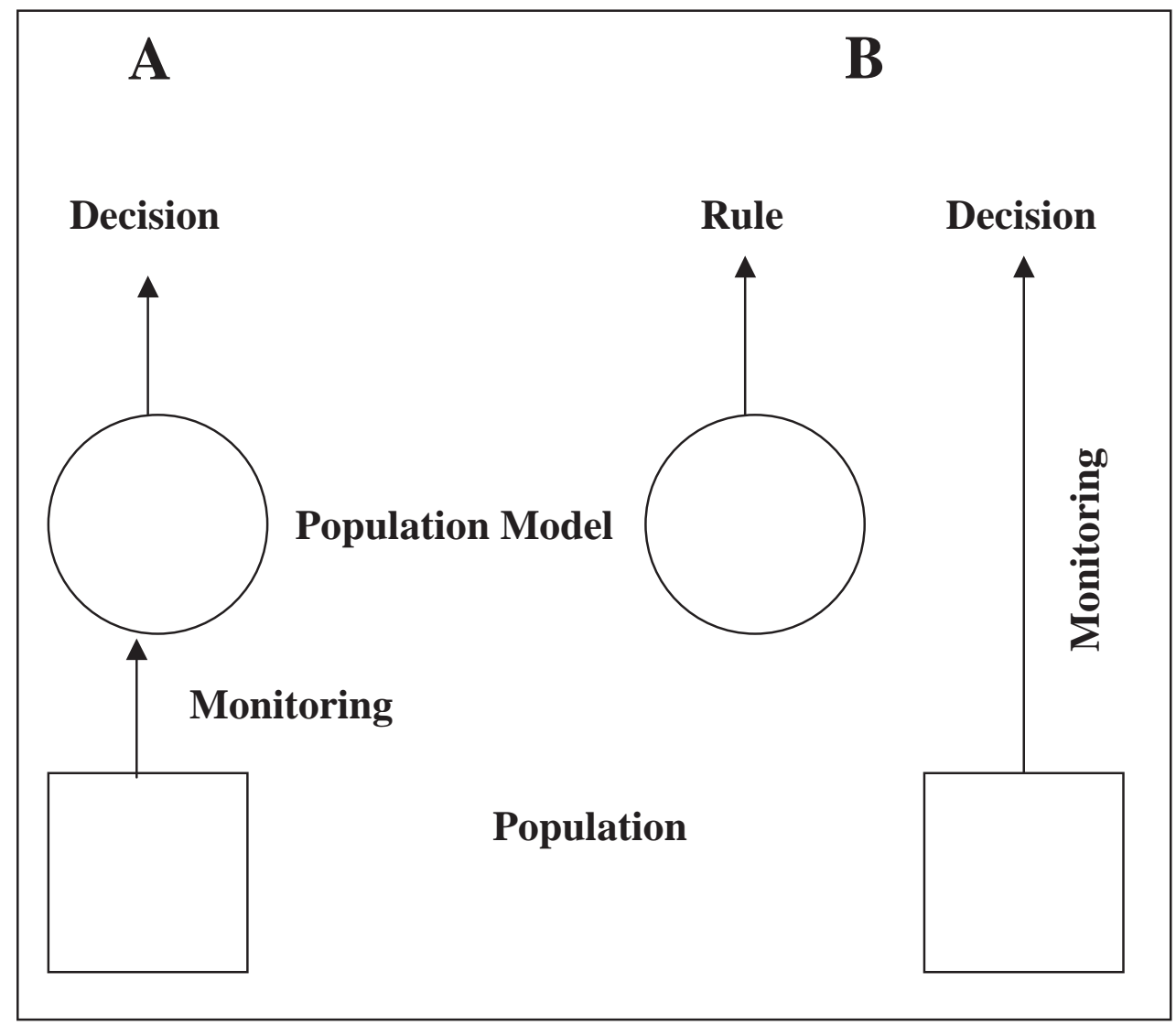

Fig. 2. Schematic of two stock assessment-management frameworks in which (A) the stock is monitored to obtain input values for a population model whose output is used annually to make management decisions, and (B) a population model is used only once to define preagreed, precautionary harvest rules i.e. actions to be taken in the event of particular monitoring results.

while downgrading other information relevant to stock status. Indicator weighting according to importance, accuracy and/or precision is controversial and must be resolved before the method can be applied successfully.

The simulation results do support the premise that the "Traffic Light" method is more precautionary than traditional assessment methods when the results are linked to simple harvest rules, especially in situations where stock recruitment relationships are weak or unknown. Traditional methods such as yield-perrecruit analysis or VPA with projections tend to be used in conjunction with rigorous, constant management strategies such as MSY or $F_{0.1}$ which ignore data extrinsic to model requirements, for example environmental changes which may be signalling a "regime shift" and a fundamental change in stock productivity. The "Traffic Light" method, in additional to making use of results from traditional analysis, can incorporate all data sources, including industry perspectives, anecdotal observations and environmental indicators. It is therefore more likely to detect such regime shifts and act upon them in a management context.

Figure 2 illustrates the fundamental difference between the "Traffic Light" method and more traditional approaches to fish stock assessment and management. It distances stock assessments from "model error" because it does not use the inevitably variable, uncertain or limited monitoring data implicitly in models (e.g. surplus production, stock-recruitment, projections from VPA, etc) to set target yields (Fig. 2 A). Instead it uses models to define a general approach to harvesting any particular stock, in the form of a rule (Fig. 2B). A rule can be set at any acceptable level of risk. Once set, the role of the model is 
completed and management essentially becomes a predefined response to monitoring outcomes. As such, it is essentially an adaptive management framework in which the rules define the limits of adaptiveness.

\section{Conclusions}

1. The "Traffic Light" method provides a way of bringing a variety of monitoring results, results from traditional stock assessment models and methods, anecdotal observations and political/ economic considerations into management decisions.

2. The "Traffic Light" method offers a transparency of method and purpose which provides intellectual and political equality to all stakeholders and quantifies the decision making process.

3. The "Traffic Light" method appears to be more precautionary than traditional stock assessment methods.

4. It should be possible to link performance reports to simple harvest control rules in a way that is consistent with shrimp stock dynamics and management requirements, creating an integrated management framework.

\section{References}

BRÊTHES, J.-C. MS 1998. Practical application of the precautionary approach. Fisheries Resource Conservation Council (FRCC) Working Paper: 13 p.
CADDY, J. F. 1996. A checklist for fisheries resource management issues seen from the perspective of the FAO Code of Conduct for Responsible Fisheries. FAO Fish. Circ., 917, 22 p.

CADDY, J. F. MS 1998. Deciding on precautionary management measures for a stock and appropriate limit reference points (LRPs) as a basis for a multi-LRP Harvest Law. NAFO SCR Doc., No. 8, Serial No. N2983, $13 \mathrm{p}$.

KOELLER, P., M. COVEY, and M. KING. MS 1999. The Scotian Shelf shrimp (Pandalus borealis fishery in 1999. Can. Stock Ass. Sec. Res. Doc., No. 172, 38 p.

MOHN, R. K., D. G. PARSONS, and L. SAVARD. 1992. Report of Canadian Atlantic Fisheries Scientific Advisory Committee Special Meeting, Invertebrates and Marine Plants Subcommittee, Shrimp Management Alternatives, December 5-8, 1989. Ottawa, Canada. Can. Tech. Rep. Fish. Aquat. Sci., 1884(iv), 30 p.

NAFO. MS 1998. Report of Scientific Council Workshop on the Precautionary Approach to Fisheries Management. NAFO SCR Doc., No. 76, Serial No. N3069, 62 p. 1998. Scientific Council Reports, p. 162-163.

PARSONS, D. G., P. J. VEITCH, and G. T. EVANS. MS 1999. Resource status of northern shrimp (Pandalus borealis) off Baffin Island, Labrador and northeastern Newfoundland - second interim review. Can. Stock Ass. Sec. Res. Doc., No. 112: 53 p.

SAVARD, L., and S. HURTUBISE. 1991. Evaluation des concentrations de crevettes nordiques (Pandalus borealis) du norde du golfe du Saint Laurent (Divisions 4RST de l'OPANO): $35 \mathrm{p}$.

SAVARD, L. MS 1999. Shrimp of the Estuary and Gulf of St. Lawrence. Fisheries and Oceans, Canada, Science Stock Status Report, C4-06: 12 p. 